\title{
The Effect of Laminate Configuration on Characteristic Lengths and Rail Shear Strength
}

\author{
FU-Kuo ChaNG AND RichaRd A. SCOTT \\ Department of Mechanical Engineering and Applied Mechanics \\ The University of Michigan, Ann Arbor, Michigan 48109
}

\author{
AND \\ GEORGE S. SPRINGER \\ Department of Aeronautics and Astronautics \\ Stanford University, Stanford, California 94305 \\ (Received November 11, 1983) \\ (Revised February 23, 1984)
}

\begin{abstract}
Tests were performed measuring the characteristic lengths in tension and in compression and the rail shear strength of Fiberite T300/1034C graphite epoxy composites. The results show the effects of geometry on the characteristic lengths. The results also indicate the variability of rail shear strength with the volume fraction of zero degree plies in the laminate.
\end{abstract}

\section{INTRODUCTION}

$\mathbf{I}$ T HAS BEEN SHOWN PREVIOUSLY [1-9] THAT A PARAMETER CALLED THE characteristic length in tension $R_{t}$ is a useful concept in the failure analysis of laminated composites containing stress concentrations. It has also been found [1-4] that a second parameter, the characteristic length in compression $\mathbf{R}_{\mathrm{c}}$ must be introduced when analyzing laminates containing loaded holes.

Although the parameters $R_{t}$ and $R_{c}$ are important in calculating the failure strengths and failure modes of laminates containing pin loaded holes, relatively little is known about the behavior of these parameters. Therefore, the major objectives of this investigation were to establish procedures for determining $R_{t}$ and $R_{c}$, and to obtain data which illustrate the effects of geometry (hole size, ply orientation) on the values of these parameters.

In order to calculate the failure strength and the failure mode, the rail shear strength $S$, and the longitudinal tensile and compression strengths $X_{t}$ and $X_{c}$ 
must also be known [1-4]. Procedures for measuring these parameters have been reported previously (e.g. ref. [10]). However, the variations of rail shear strength with the volume fraction of zero degree plies have not yet been established. Therefore, a further objective was to determine the variations in $\mathrm{S}$ for laminated composites.

\section{EXPERIMENTAL WORK}

The apparatus and procedure which were used to determine the characteristic length in tension $R_{t}$, the characteristic length in compression $R_{c}$, and the rail shear strength $S$ are described below.

\section{Characteristic Length in Tension, $\mathbf{R}_{\mathbf{t}}$}

The characteristic length $R_{t}$ was determined using rectangular specimens with an open hole in the center of the specimen. Tests were performed with specimens having different ply orientations, different hole sizes (1/8 to $1 / 2$ in diameter) and different dimensions ( 0.5 to 2 in width). During each test, the specimen was subjected to a tensile load and the ultimate load was recorded. In addition, (after failure) the specimens were inspected visually to establish the mode of failure.

From the measured tensile strength the value of $R_{t}$ was determined as follows.

At the failure load, the stresses in the laminate were calculated using the model described in Reference [3] for a laminate containing an open hole. The stresses calculated in each ply along the $\theta=90$ line were substituted into the Yamada-Sun failure criterion [1-4]. The point along this line was found at which the value of the parameter $e$ in the Yamada-Sun failure criterion became unity. The distance between this point and the edge of the hole was taken to be $R_{t}$. The tests were done four times for each specimen configuration and an average value of $R_{t}$ was calculated. The values of $R_{t}$ thus measured are presented in the next section.

\section{Characteristic Length in Compression, $\mathbf{R}_{c}$}

The characteristic length $R_{c}$ was determined by the following method. $A$ single hole was drilled into each specimen. The geometries of the specimens are given in Table 1. The specimen was inserted in the fixture described in the Appendix of Reference [3]. Note that in these tests there was a pin inside the hole. During the tests a tensile load was applied, as is discussed in Reference [4].

From the measured tensile strength, the characteristic length $\mathbf{R}_{\mathrm{c}}$ was determined as follows. The stresses were calculated using the model described in Reference [3] for a loaded hole. A value of $\mathbf{R}_{c}$ was assumed and the characteristic curve was constructed in the manner given in [3]. The value of the parameter $e$ in the Yamada-Sun failure criterion was determined in each ply along a segment of the characteristic curve, ranging from $\theta=15$ to $\theta=-15$ 
Table 1. Properties of fiberite T300/1034C graphite/epoxy composite.

\begin{tabular}{llc}
\hline Longitudinal Young's Modulus, $E_{x}$ & $=21300000 \mathrm{psi}$ \\
Transverse Young's Modulus, $E_{\mathrm{y}}$ & $=1700000 \mathrm{psi}$ \\
Shear Modulus, $\mathrm{G}_{\mathrm{xy}}$ & $=897000 \mathrm{psi}$ \\
Poisson's Ratio $\mu_{\mathrm{xy}}$ & 0.3 \\
Longitudinal Tensile Strength, $\mathrm{X}_{\mathrm{t}}$ & $=251000 \mathrm{psi}$ \\
Longitudinal Compressive Strength, $\mathrm{X}_{\mathrm{c}}=200000 \mathrm{psi}$ \\
Rail Shear Strength, $\mathrm{S}=\mathrm{S}_{\mathrm{so}}$ & $=19400 \mathrm{psi}$ \\
Characteristic Length in Tension, $\mathrm{R}_{\mathrm{t}}$ & $=0.018 \mathrm{in}$ \\
Characteristic Length in Compression, $\mathrm{R}_{\mathrm{c}}=0.07 \mathrm{in}$ \\
\hline
\end{tabular}

( $\theta$ is zero in the direction of the applied load [3]). The procedure was repeated for different assumed values of $R_{c}$ until (in any ply) the value $e=1$ was reached along the characteristic curve segment $(-15 \leqslant \theta \leqslant+15)$. This value was then taken to be $R_{c}$. The measured values of $R_{c}$ are presented in the next section.

\section{Laminate Rail Shear Strength, $\mathbf{S}$}

Rail shear tests were performed to measure the laminate shear strength. Cross ply [0/90] $]_{s}$ laminates made of either 20 or 24 plies were used in the tests. Laminates with different volume fractions $v_{0}$ of 0 plies were tested. $v_{0}$ is the number of zero degree plies divided by the total number of plies.

The specimens ranged from 7.75 to 8.0 in. in length and 1.5 to 2.0 in. in width. These specimen dimensions were selected because it was demonstrated by previous investigators that for such specimens, edge effects are negligible $[7,8]$.

Eight $3 / 16$ in diameter holes were drilled along two sides of the specimens, as illustrated in Figure 1. The specimen were placed between a rail-shear fixture. The geometry and dimension of this fixture are given in Figure 1. The specimen was fastened to the rail-shear fixture by 16 bolts. The bolts were tightened to at least $80 \mathrm{ft}-\mathrm{lbf}$ torque.

The shear tests were performed by placing the rail-shear fixture into a mechanical testing machine and by applying a compressive load. The ultimate failure load of the laminate was recorded.

\section{RESULTS}

Tests were performed to determine the characteristic lengths $R_{t}$ and $R_{c}$ and the rail-shear strength $S$ of Fiberite T300/1034-C composites. The data are presented in Figures 2-4. The detoiled data can be found in Reference [4]. The data indicate the sensitivities of $R_{t}, R_{c}$ and $S$ to such parameters as specimen geometry and laminate configuration. 


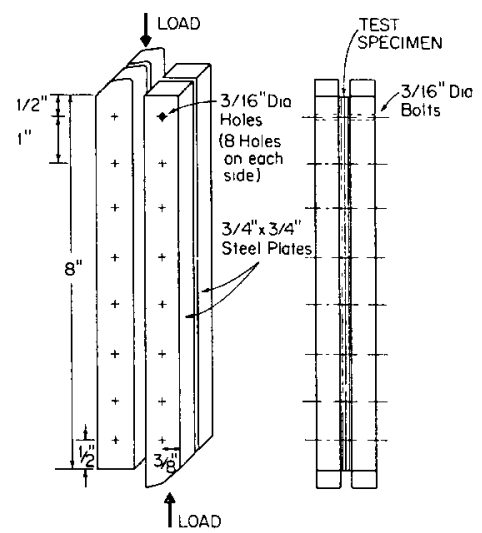

Figure 1. Schematic of rail shear test fixture.

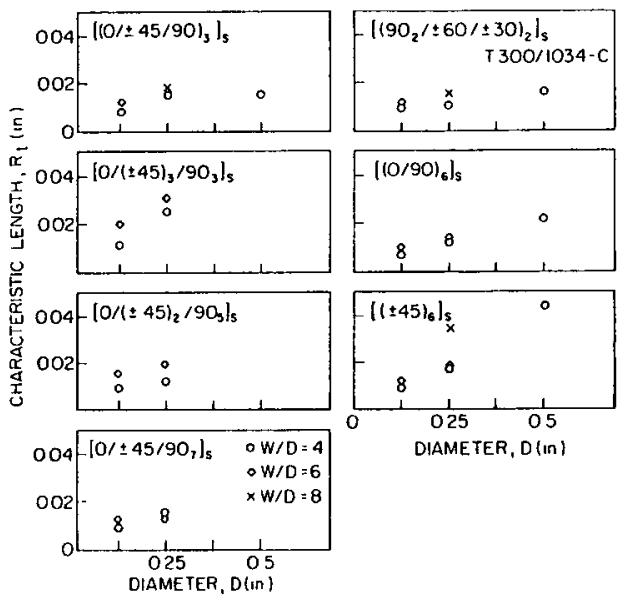

Figure 2. Characteristic length in tension $R_{\mathrm{s}}$ as a function of hole diameter, width ratio, and ply orientation.

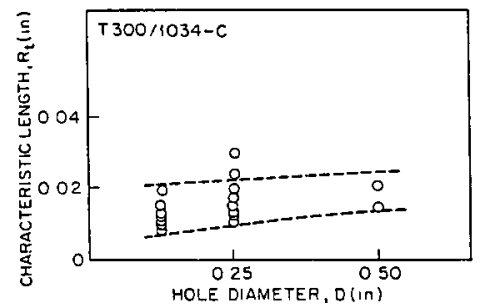

Figure 3. Variation of characteristic length with hole diameter. Data are for laminate configurations given in Figure 2. 


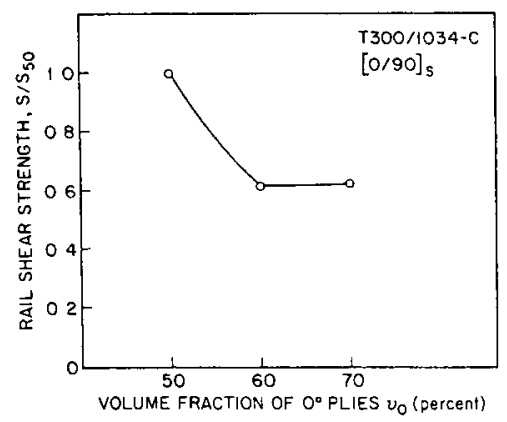

Figure 4. Variation in rail shear strength with the volume fraction of 0 degree plies of cross ply laminates. o data. - fit to data. $S_{50}=$ rail shear strength of laminates having $50 \%$ zero degree plies by volume $(19,400$ psi).

The material properties used in deducing $R_{t}, R_{c}$ and $S$ from the measured data are listed in Table 1 . In this table the average values of $R_{t}, R_{c}$ and $S$ obtained in this investigation are also included.

\section{Characteristic Lengths in Tension, $\mathbf{R}_{\mathbf{t}}$}

The characteristic length $R_{t}$ was determined using laminates with different geometries and different ply orientations. The data are summarized in Figures 2 and 3 . Each data point in these figures is the average of four measurements. Figure 2 shows the variations in $R_{t}$ with laminate lay up. In Figure 3 all but one set of data are presented in a single plot.

The results in Figure 2 show that the value of $R_{t}$ depends on the hole diameter, the width ratio (W/D), and the ply orientation. The value of $R_{t}$ increases with increasing hole diameter (Figures 2 and 3).

Different investigators, such as Whitney and Nuismer $[6,7]$ and York et al [5], used different definitions of characteristic length from the one proposed here. Their definitions were not used here since they involve determination of the unnotched plate strength, and so additional experiments would have had to be performed. Secondly, it was found that for the lay-up [ \pm 45$]$, their procedures led to values of $R_{t}$ that were on the order of magnitude bigger than any reported previously. It is still noteworthy that an increase in characteristic length with hole diameter was also observed by Whitney and Nuismer $[6,7]$ and by York et al [5], in their tests with T300/5208 and AS-3501-6 graphite/ epoxy laminates.

It is difficult to discern definite trends in $\mathbf{R}_{\mathbf{t}}$ with width ratio and ply orientation. In calculating the strengths of loaded holes, the $R_{t}$ value appropriate to the laminate and hole configuration should be used. When this value is unavailable, an approximate value of $R_{t}$ has to be chosen. Fortunately, it was found that the predicted values of the failure load were insensitive to the value of $R_{t}$. For example, the failure strengths of loaded holes in Fiberite 
T300/1034-C laminates were calculated with the values of $R_{t}=0.007,0.018$, and $0.04 \mathrm{in}$. The use of the lower $(0.007 \mathrm{in})$ and higher $(0.04 \mathrm{in}) \mathbf{R}_{\mathrm{t}}$ values yielded failure strengths which are only about 10 percent to 20 percent different from the failure strength obtained by the average $R_{t}$ value $\left(R_{t}=0.018\right.$ in).

\section{Characteristic Length in Compression, $\mathbf{R}_{c}$}

The value of $\mathbf{R}_{c}$ was determined for four different ply orientations. The data are summarized in Table 2. Each $R_{c}$ value in this table is the average of four measurements.

The values of $R_{c}$ were obtained from data generated using loaded holes and from the Yamada-Sun failure criterion. Both the longitudinal and shear stresses play a role in this criterion. Thus, both of these stresses may affect the value of $\mathbf{R}_{\mathrm{c}}$. The shear stress has a significant effect in those laminates in which the shear stress to shear strength ratio $\left(o_{x y} / S\right)$ is comparable to the longitudinal stress to longitudinal compressive strength ratio $\left(\sigma_{x} / X_{c}\right)$. This situation arises, for example, in $[0 / 90]_{s}$ and $[ \pm 45]_{s}$ laminates.

In calculating $\mathbf{R}_{c}$, the stresses were assumed to vary linearly with strains. As will be discussed subsequently for shear stresses this assumption may be invalid. This assumption may have affected the values of $R_{c}$, especially for the two cross-ply laminates in Table 1 . The effects introduced in $\mathbf{R}_{\mathrm{c}}$ by the assumption of linear stress-strain relationship is unknown; therefore, the value of $R_{c}(=0.07$ in) obtained for quasi-isotropic laminates might be best for calculating failure strengths and failure modes.

\section{Rail Shear Strength, S}

Rail shear tests were performed with symmetric cross-ply laminates [0/90] having different volume fractions of zero degree plies. The rail-shear strength depends on the volume fraction of the zero degree plies in the laminates. At volume fractions above 50 percent the rail shear strength decreases (Figure 4). Therefore, when the volume fraction of zero-degree plies is higher than 50 percent, the rail-shear strength corresponding to the appropriate volume fraction should be used in calculating the failure strength and the failure mode.

The value of the rail shear strength given in Table 1 corresponds to the rail

Table 2. The characteristic length in compression $R$ for fiberite $T 300 / 1034 C$. Data obtained for $D=0.25 \mathrm{in}, W=2.0 \mathrm{in}, L=7.0 \mathrm{in}, E=1.25 \mathrm{in}$.

\begin{tabular}{lc}
\hline Ply Orientation & Characteristic Length $R_{c}$ (in) \\
\hline$\left[(0 / \pm 45 / 90)_{3}\right]_{s}$ & 0.07 \\
{$\left[\left(900_{2} / \pm 60 / \pm 30\right)_{2}\right]_{s}$} & 0.08 \\
{$\left[(0 / 90)_{6}\right]_{s}$} & 0.09 \\
$\left.[ \pm 45)_{6}\right]_{s}$ & 0.13 \\
\hline
\end{tabular}


shear strength of cross ply $[0 / 90]_{\mathrm{s}}$ laminates having 50 percent zero degree plies by volume.

It was observed that the shear stress to shear strain relationship was nonlinear. The assumption of linear stress-strain relation may result in some error in the calculated values of the failure strength, especially for laminates consisting predominantly of $[0 / 90]_{\mathrm{s}}$ and $[ \pm 45]_{\mathrm{s}}$ plies.

\section{CONCLUDING REMARKS}

As the foregoing results show the characteristic lengths $R_{t}$ and $R_{c}$ and the rail shear strength $S$ depend on the laminate configuration. Therefore, the values appropriate to the geometry and the ply orientation should be used in calculating the failure strengths and failure modes of laminates containing pin loaded holes. However, in many cases the failure strength and failure mode are insensitive to the precise values of $R_{1}$ and $R_{c}$. This seems to be the case, for example, for quasi-isotropic laminates. For this case approximate values suffice for the calculations.

\section{ACKNOWLEDGEMENTS}

This work was supported by the Mechanics and Surface Interactions Branch, Nonmetallic Materials Division, Materials Laboratory, Air Force Wright Aeronautical Laboratories, Wright-Patterson AFB, Ohio. Dr. S. W. Tsai was the project engineer.

\section{REFERENCES}

1. Chang, F. K., Scott, R. A., and Springer, G. S., "Strength of Mechanically Fastened Composite Joints," J. of Composite Materials, Vol. 16, pp. 470-494 (1982).

2. Chang, F. K., Scott, R. A., and Springer, G. S., "Strength of Mechanically Fastened Composite Joints," Air Force Wright Aeronautical Laboratories, Technical Report AFWALTR-82-4095, 1982.

3. Chang, F. K., Scott, R. A., and Springer, G. S., "Failure of Composite Laminates Containing Pin Loaded Holes-Method of Solution," J. of Composite Materials Vol. 18, pp. 255-278 (1984).

4. Chang, F. K., Scott, R. A., and Springer, G. S., "Strength of Bolted Joints in Laminated Composites," Air Force Wright Aeronautical Laboratories, Technical Report AFWALTR-83-4029, 1983.

5. York, J. L., Wilson, D. W., and Pipes, R. B., "Analysis of Tension Failure Mode in Composite Bolted Joints," J. of Reinforced Plastics and Composites, Vol. 1, pp. 141-153 (1982).

6. Whitney, J. M., and Nuismer, R. J., "Stress Fracture Criteria for Laminated Composite Containing Stress Concentrations," J. of Composite Materials, Vol. 8, pp. 253-265 (1974).

7. Nuismer, R. J., and Whitney, J. M., "Uniaxial Failure of Composite Laminates Containing Stress Concentrations," Fracture Mechanics of Composites, ASTM STP 593, pp. 117-142 (1975).

8. Nuismer, R. J., and Labor, J. D., “Applications of the Average Stress Failure Criterion: Part I-Tension," J. of Composite Materials, Vol. 12, pp. 238-249 (1978).

9. Nuismer, R. J., and Labor, J. D., “Applications of the Average Stress Failure Criterion: Part Il-Compression," J. of Composite Materials, Vol. 13, pp. 49-60 (1979).

10. Yamada, S. E., and Sun, C. T., “Analysis of Laminated Strength and its Distribution," J. of Composite Materials, Vol. 12, pp. 275-284 (1978). 